\title{
A questão democrática na área da Saúde*
}

| ${ }^{1}$ Hesio Cordeiro, ${ }^{2}$ José Luís Fiori, ${ }^{3}$ Reinaldo Guimarães |

\footnotetext{
${ }^{1}$ Um dos fundadores e ex-professor do Instituto de Medicina Social da Universidade do Estado do Rio de Janeiro (IMS/UERJ), ex-reitor da UERJ، ex-presidente do INAMPS

2 Universidade Federal do Rio de Janeiro. Rio de Janeiro-RJ, Brasil (jlfiori@uol.com.br). ORCID: 0000-0002-8132-7181

${ }^{3}$ Núcleo de Bioética e Ética Aplicada, Universidade Federal do Rio de Janeiro. Rio de Janeiro-RJ, Brasil (reinaldo.guimaraes47@gmail.com). ORCID: 0000-0002-0138-9594
}

DOI: http://dx.doi.org/10.1590/S0103-73312021310302

É praticamente consensual entre os especialistas o diagnóstico que, a partir da década de 60, vem piorando gradativamente o nível de vida da população. Aumentaram, significativamente, a mortalidade infantil, as doenças endêmicas, as taxas de acidentes do trabalho, o número de doentes mentais etc. Pioraram, igualmente, as condiçóes de saneamento, a poluição ambiental e os níveis de nutricionais chegaram ao ponto de preocupar as autoridades - hoje, um tanto pessimistas com relação ao que chamam de "miséria absoluta".

Cresce a um só tempo a mobilização contra o desemprego, os baixos salários e suas péssimas condiçôes de vida. Cresce também, e mais especificamente, a irritação

\footnotetext{
* A elaboração deste texto começou, em 1975, com diversas consultas pelos autores a entidades da sociedade brasileira, tomou sua forma final e começou a circular, em 1976, e foi apresentado pelo Centro Brasileiro de Estudos de Saúde (CEBES) no 1o Simpósio sobre Política Nacional de Saúde na Câmara Federal, em outubro de 1979. Depois dessa trajetória inicial, o texto se transformou num verdadeiro manifesto do movimento sanitário dos anos 1980. Publicado originalmente na revista Saúde em Debate, no 9, jan-mar. 1980.
} 
da população contra as filas, a burocracia, a corrupção e os custos da má atenção médica que recebem. Crescem, finalmente, as reclamaçóes e reivindicaçôes sindicais contra os convênios e contratos com as empresas médicas.

Enquanto isso acontece, a medicina brasileira vive uma profunda crise. Exacerbam-se as críticas à sua qualidade. Questiona-se cada vez mais sua eficiência. Acusam-se os médicos de desleixo e desnaturada avidez salarial. Os donos dos hospitais ameaçam fechá-los porque seus lucros estão baixos.

É neste contexto que se situa a maior parte do material que vem sendo veiculado pelos meios de comunicação de massa. Inúmeros elementos objetivos sustentam a parcial veracidade destas acusaçôes. Entretanto, o que só recentemente está vindo à luz, em forma ainda um tanto encoberta, são as reais causas das distorçôes detectadas. As raízes últimas na anarquia instaurada na assistência médica e da insolvência sanitária da população: a mercantilizaçáo da medicina promovida em forma consciente e acelerada por uma política governamental privatizante, concentradora e antipopular.

Política que substitui a voz da população, pela sabedoria dos tecnocratas e pelas pressóes dos diversos setores empresariais. Política de saúde que acompanha, em seu traçado, as linhas gerais de posicionamento socioeconômico do governo: privatizante, empresarial e concentrador da renda, marginalizando cerca de $70 \%$ da população benefícios materiais e culturais do crescimento econômico. Política de saúde, ainda, que reduziu ao mínimo os gastos em saúde pública, privilegiando a assistência médico-hospitalar curativa e de alta sofisticação, ainda quando o quadro sanitário do país indique a enorme importância dos "velhos" problemas: esquitossomose, Chagas, malária, desnutrição, altos índices de mortalidade infantil, combinados com a emergência de novos padróes de mortalidade urbana (câncer, doenças cardiovasculares, acidentes, violência etc.). Política de saúde, enfim, que esquece as necessidades reais da população e se norteia exclusivamente pelos interesses da minoria constituída e confirmada pelos donos das empresas médicas e gestores da indústria da saúde em geral (CORDEIRO, 1980).

Exemplo recente desta forma de política elitista e antipopular é a tentativa da criação do cheque-consulta, cujo único objetivo é satisfazer aos interesses dos produtores de serviços, acenando à população com a ilusão de um melhor acesso aos serviços de saúde.

Face a esta política de caráter essencialmente antidemocrático, a grande maioria dos profissionais de saúde encontra-se, hoje, colocada na trincheira de uma batalha 
inglória a tentar remediar os males de um planejamento ineficaz para uma população carente e subnutrida, com técnicas às vezes tão ou mais perigosas que as próprias doenças que deseja eliminar. Por outro lado, a população marginalizada das decisôes sobre a política de saúde, da mesma forma que a maioria das decisóes sobre a vida nacional, financia um sistema que muito pouco ou nada lhe oferece em troca.

Frente a este quadro, é dever da população e dos profissionais de saúde, nos locais de trabalho e reunidos em torno de suas entidades representativas, apresentar seu diagnóstico da situação. Mais ainda, somando-se ao clima de debates que hoje caracteriza a conjuntura política nacional, avançar e propor plataformas de luta que busquem reunir suas aspirações na linha de constituição de uma medicina democrática.

É nesse sentido que o Centro Brasileiro de Estudos de Saúde vem apresentar sua contribuição a este debate e a esta luta. $\mathrm{O}$ diagnóstico apresentado já indica as grandes linhas de uma proposta, limitando responsabilidades e definindo os principais obstáculos que se interpóem hoje, no Brasil, entre os ideais democráticos e as possibilidades de resposta e adequação real do nosso sistema de saúde àqueles ideais. Por uma Saúde autenticamente democrática entende-se:

1. O reconhecimento do direito universal e inalienável, comum a todos os homens, à promoção ativa e permanente de condiçôes que viabilizem a preservação de sua saúde.

2. O reconhecimento do caráter socioeconômico global destas condiçôes: emprego, salário, nutrição, saneamento, habitação e preservação de níveis ambientais aceitáveis.

3. O reconhecimento da responsabilidade parcial, porém, intransferível das açôes médicas propriamente ditas, individuais e coletivas, na promoção ativa da saúde da população.

4. O reconhecimento, finalmente, do caráter social deste direito e tanto da responsabilidade que cabe à coletividade e ao Estado em sua representação, pela efetiva implementação e resguardo das condiçôes supramencionadas.

Por isso, são necessárias medidas que:

1. Obstaculizem os efeitos mais nocivos das leis de mercado na área da Saúde, ou seja, detenham o empresariamento da medicina.

2. Transformem os atos médicos lucrativos em um bem social, gratuito, à disposição de toda a populaçẫo. 
3. Criem um Sistema Único de Saúde.

4. Atribuam ao Estado a responsabilidade total pela administração deste sistema.

5. Deleguem ao Sistema Único de Saúde a tarefa de planificar e executar uma política nacional de saúde; que inclua: a pesquisa básica, a formação de recursos humanos, a atenção médica individual e coletiva, curativa e preventiva, o controle ambiental, o saneamento e a nutrição mínima à sobrevivência de uma população hígida.

6. Estabeleçam mecanismos eficazes de financiamento do sistema, que não sejam baseados em novos gravames fiscais sobre a maioria da população, nem em novos impostos específicos para a Saúde. O financiamento do Sistema Único deverá ser baseado numa maior participação proporcional do setor Saúde nos orçamentos federal, estaduais e municipais, bem como no aumento da arrecadação decorrente de uma alteração fundamental no atual caráter regressivo do sistema tributário.

7. Organizem esse sistema de forma descentralizada, articulando sua organização com a estrutura político-administrativa do país em seus níveis federal, estadual e municipal, estabelecendo unidades básicas, coincidentes ou não com os municípios, constituídas por aglomerações de população que eventualmente reuniriam mais de um município ou desdobrariam outros de maior densidade populacional. Essa descentralização tem por fim viabilizar uma autêntica participação democrática da população nos diferentes níveis e instâncias do sistema, propondo e controlando as açóes planificadas de suas organizações e partidos políticos representados nos governos, assembleias e instâncias próprias do Sistema Único de Saúde.

8. Essa descentralização visa, por um lado, a maior eficácia, permitindo maior visualização, planificação e alocação dos recursos segundo as necessidades locais. Mas, visa, sobretudo, ampliar e agilizar uma autêntica participação popular a todos os níveis e etapas na política de Saúde.

Este, talvez o ponto fundamental desta proposta, negador de uma solução meramente administrativa ou "estatizante". Trata-se de canalizar as reivindicaçóes e proposiçóes dos beneficiários, transformando-os em voz e voto em todas as instâncias.

Evita-se, também, com isso, uma participação do tipo centralizador, tão cara ao espírito corporativista e tão apta às manipulaçôes cooptativas de um Estado fortemente centralizado e autoritário, como tem sido, tradicionalmente, o Estado brasileiro. 
9. Estabeleçam um estatuto de convivência entre a prática assalariada vinculada ao Sistema Único de Saúde e a autêntica prática de consultórios particulares que têm tradição na medicina brasileira.

10. Definam uma estratégia específica de controle sobre a produção e distribuição de medicamentos, assim como de produção e/ou importação e consumo de equipamentos médicos. Que esta estratégia tenha presente as necessidades reais, majoritárias e regionalizadas da população, reduzindo ao mínimo os gastos e a sofisticação desnecessária.

Estas opçóes políticas conduzem a uma proposta de transformação profunda no atual sistema de saúde, cujas medidas iniciais sejam:

I - Criar o Sistema Único de Saúde (SUS).

II - Outorgar ao Ministério da Saúde a direção do SUS, com a tarefa de planificar e implantar em conjunto com os governos estaduais e municipais a Política Nacional de Saúde. O órgão deve ter poder normativo e executivo, inclusive sobre o setor privado e empresarial, sendo controlado permanentemente pela população, através de suas organizaçôes representativas, via mecanismos claramente estabelecidos e institucionalizados.

III - Definir a Política de Assistência Médica, atualmente levado a cabo pelo INAMPS, já então enquadrado e disciplinado pelo órgão diretor do SUS, mediante a suspensão imediata dos convênios e contratos de pagamento por unidades de serviços para a compra de atos médicos ao setor privado empresarial; substituindo-os por subsídios globais; estabelecer mecanismos efetivos de controle destas unidades contratadas que impeçam consequências danosas como o aviltamento dos salários dosa profissionais e a diminuiçáo da qualidade do atendimento; controle a ser exercido em conjunto por um representante do Sistema Único de Saúde com assento permanente na direção dessas unidades.

IV - Criar imediata, ainda que progressivamente, com os recursos antes dispendidos com os convênios e outros, uma rede nacional, devidamente regionalizada, de ambulatórios e postos de saúde próprios, voltados para a aplicação de medidas preventivas, articuladas com a assistência médica primária, de casos de emergência e acidentes de trabalho. Para o funcionamento desses postos, deverão ser utilizados médicos funcionários do Sistema Único e, sobretudo, pessoal auxiliar, cuja formação deverá ser estimulada com veemência. 
V - Definição de uma política para área rural, adequada às reais necessidades dessa população, descondicionando a prestação de assistência médica da satisfação de interesses eleitorais de grupos partidários.

VI - Redefinir a atual política do FAZ, para que passe a financiar a expansão da rede básica dos serviços de saúde.

VII - Privilegiar as medidas de controle do meio ambiente, particularmente aquelas destinadas à redução de doenças endêmicas, como Chagas, esquistossomose, malária etc.

VIII - Planejar a formação e distribuição de profissionais de saúde, definindo as prioridades para a formação de pessoal não especializado e especializado.

IX - Definir uma política de produção e distribuição de medicamentos e equipamentos médicos orientada pela simplificação e eficácia tecnológica e dirigida à redução da dependência ao capital estrangeiro através de:

- maior participação estatal na pesquisa, formação de pesquisadores e desenvolvimento de tecnologia nacional dirigida à produção de matérias-primas fundamentais à industrialização de medicamentos essenciais; de modo similar ao que originalmente propunha o próprio projeto ou Central de Medicamentos;

- controle de remessas de lucros para o exterior;

- controle efetivo da qualidade e da quantidade dos medicamentos comercializados;

- importação apenas daqueles equipamentos e fármacos que tenham tido sua eficácia comprovada através da utilização por um período mínimo de cinco anos.

O conjunto dessas reivindicaçóes conforma uma primeira etapa na formulaçáo de uma plataforma de luta em prol de uma autêntica democratização da medicina e da Saúde brasileira.

Não pretende ser executiva nem abranger detalhamentos administrativos de implementação. Não é seu objetivo. Define apenas as grandes linhas que deverão orientar, em nosso entender, as decisóes políticas fundamentais.

Abre-se, a partir deste momento, um debate democrático, o mais amplo e fértil possível, com todas as entidades e instituiçôes interessadas na soluçâo da crise atual da medicina brasileira. Debate que aprofunde os pontos indicados, levando à formulação mais acabada de uma plataforma que agrupe e mobilize médicos e não 
médicos na luta contra a atual política de governo para a saúde e a favor de uma medicina democrática.

O CEBES (CEBES, 1980), dentro da perspectiva da democratização dos serviços de saúde, entende também que devam ser atendidas as justas reivindicaçôes dos movimentos sociais no setor, no sentido de:

a. Desvincular os conselhos profissionais do Ministério do Trabalho, a exemplo da OAB.

b. Estabelecer salários justos que dignifiquem a atividade profissional, a estabilidade no emprego e melhores condiçóes de trabalho.

c. Ser coibido o uso do saber e autoridade quando usada para praticar ou acobertar atos de violência física ou moral contra a pessoa humana.

d. Eliminar toda e qualquer discriminação social, religiosa, política e ideológica, na admissão de profissionais para cargos públicos ou privados.

e. Modificar os atuais currículos de formação de profissionais, adaptando-os às atuais necessidades sociais, enfatizando a área de Saúde Coletiva.

f. Regularizar a situaçáo de diferentes profissionais, como por exemplo, assinando a carteira de trabalho para residentes e regulamento em todos os níveis, a carteira de sanitaristas.

g. Imediata readmissão de professores, médicos, cientistas etc., atingidos pelos atos excepcionais.

h. Recusar na sua totalidade o atual projeto da CLT, unindo-se à luta de todos os trabalhadores brasileiros.

\section{Referências}

CEBES - CENTRO BRASILEIRO DE ESTUDOS DE SAÚDE. A questão democrática na área da Saúde. Saúde em Debate. 9:11-13, 1980.

CORDEIRO, H. A indústria da saúde no Brasil. Rio de Janeiro: Ediçôes Graal, 1980. 